\title{
Interdisciplinary Science and Research: A Novel Program to Advance Student Preparation in STEM
}

\author{
Jennifer A. Ufnar', and Virginia L. Shepherd ${ }^{1,2}$ \\ ${ }^{1}$ Department of Teaching and Learning, Vanderbilt University; ' ${ }^{2}$ Center for Science Outreach, Vanderbilt University \\ Keywords: STEM, Interdisciplinary, Research-based \\ Publication date: January 22, 2018 \\ DOI: https://doi.org/10.15695/jstem/v1i1.6
}

\begin{abstract}
To address the need for STEM reform in K-12 schools, this article describes the design and implementation of a rigorous, interdisciplinary science and research program (ISR) in two local high schools (HS-S and HS-H). The ISR, adapted from the successful School for Science and Math at Vanderbilt program, provides seven courses over four years that focus on the development of critical thinking skills and the ability to construct and perform hypothesis-driven research projects. The courses are co-taught by a science teacher (masters or doctoral level) and a Ph.D. scientist. Overall, students in both programs showed higher science end-of-course test scores and ACT composite scores compared to their non-ISR peers, completed research internships at Vanderbilt, and presented their research at local and regional meetings. Currently 62 of the 77 ISR graduates are attending college, with $62 \%$ of the declared majors in STEM areas. As the programs have matured, challenges such as low student preparation (ISR-S) and competition with other school academic offerings (ISR-H) have been addressed, resulting in increased numbers of students participating in the program. The school district has demonstrated the value of the ISR program by providing funding for the scientists and expanding to a third school in 2016.
\end{abstract}

\section{INTRODUCTION}

Recent national agencies and reports have called for increased emphasis on STEM education to better prepare students for jobs in the 21 st century. It has been estimated that by 2020 careers across all STEM fields will increase by an average of $14 \%$, while some jobs such as biomedical engineers will increase by over $60 \%$ (Department of Education, 2015). However, the U.S. is falling behind internationally, and now ranks 22nd in science and 29th in math among industrialized countries (ACT, 2017a). Based on national and international tests, less than $30 \%$ of U.S. college students have an interest in a career in a STEM field (ACT, 2016a), and in Tennessee less than $20 \%$ of high school graduates met the benchmark for college readiness in STEM according to the latest ACT report (ACT, 2016b). The good news is that interest in STEM is increasing both nationally and in Tennessee. In the past decade, interest in STEM increased from $24 \%$ to $28 \%$ nationally and by several percentage points for most ethnic groups in Tennessee (Alliance for Science and Technology Research, 2016). Our challenge now as stated by the recent Committee on STEM Education, is to improve STEM education from preK through 12th grade, and to increase and sustain youth engagement with STEM (National Science and Technology Council, 2013).
Focusing on STEM provides a way of approaching problems and thinking critically about how to design solutions to real-world challenges that will be applicable to students preparing for all types of careers. As then President Obama stated in 2015 "[Science] is an approach to the world, a critical way to understand and explore and engage with the world, and then have the capacity to change that world..." (Department of Education, 2015). The focus of the current study is a description of a novel four-year STEM program and the impact on students gaining important program solving skills, and preparation for college and potentially to pursue STEM majors.

In the current study, we report results from the design and implementation of a novel four-year rigorous progression of STEM courses called the Interdisciplinary Science and Research (ISR) program. This is a description of a program that other universities may wish to adopt and adapt; a more formal research study with a well-matched comparison group is currently underway in partnership with the school district Research Office. The ISR was adapted from the highly successful School for Science and Math at Vanderbilt (SSMV) that is now starting its 11th year (Eeds et al., 2014). The SSMV program brings 26 highly talented students from 
each high school grade to campus for one day per week. The admissions process is based on academic achievement and demonstrated motivation, thus limiting the population of students who have access to the program. To expand the opportunity to more students and to provide access to students who are not able to balance the day away from their regular classes, the Vanderbilt Center for Science Outreach (CSO), in partnership with the local school district (Metro Nashville Public Schools-MNPS), adapted the SSMV for inclusion in two high schools (HS-S and HS-H) in the regular school day as a four-year series of rigorous, research-based courses.

The ISR program was initiated with several defined outcomes: 1) to increase achievement test scores (end-of-course and ACT);2) to increase the number of students who participate in the summer research experience for high school students program (REHSS); 3) to increase the number of students who meet the ACT college-ready benchmark); 4) to increase the number of students who graduate from high school and matriculate at a four-year college; 5) to increase the number of students who matriculate at a top tier university; 6) to increase the number of students who earn dual enrollment course credits in partnership with a local university; 7) to increase the number of students who declare and complete a STEM major in college. The current study described the impact of this in-school STEM research program on attainment of these benchmarks through an examination of 77 graduates of the two ISR programs.

\section{METHODS}

Student tracking. Data were collected for 77 students who completed the ISR program between the years 2013-2016 (HS-S) and 2014-2016 (HS-H). Information for individual ISR students was provided throughout their high school years by school administrators. Following graduation, student information including colleges attended and majors selected was collected through a subscription to the National Student Clearinghouse (2017), which tracks student enrollment and degree records for those students attending colleges that participate in the Clearinghouse. For the total of 77 graduates, 17 records were not found, either because the student did not attend a college or because the college is not a Clearinghouse participant. Four ISR graduates who did not show up in the Clearinghouse database were located on social media sites or from school administrators, bringing the total number of students that had college attendance records to 64 .

Data collection for partner schools. Aggregate data for whole student populations of the State of Tennessee, MNPS, HS-S, HS-H, and the MNPS academic magnet high school (HS-A) were collected from the online State of Tennessee Report card (State Report Card, 2017). Aggregate data for the partner school students was obtained from the schoolbased leadership team.

Confidentiality of data. Students were assented and parents consented through an Institutional Review Board-approved process. Consent documents were scanned and maintained on a password-protected server. All paper records were maintained in locked file cabinets. Electronic files were kept on a secure server maintained by the lead institution and password protected.

\section{RESULTS}

ISR program design and implementation. The ISR program began in 2010 as a collaboration between the MNPS school district and the CSO, funded through federal grants and contracts. CSO staff and district and school administrators met in the spring to plan the opening of an SSMV-like program in one MNPS high school (HS-S), with plans to eventually expand to two additional schools. Two new state of the art science labs were installed in HS-S, and teachers and scientists were identified to co-teach the initial course of study. The plan was to begin with one 9th and one 10th grade class, expanding in future years to fill out the entire fouryear program. The scientist-teacher ISR team met with CSO staff for four weeks during the summer to begin planning the initial courses.

In 2012, the ISR program was expanded to a second high school (HS-H), following the same course progression and format, and led by a Ph.D. scientist-teacher team. The two high schools that were selected by MNPS have specific characteristics and features that determined the design and implementation of the ISR program in those schools. As shown in Table 1, the demography and student achievement scores for each of these schools are quite different.

Table 1. Exploratory Factor Analysis Eigenvalues

\begin{tabular}{lcccc}
\hline & TN & MNPS & HS-H & HS-S \\
\hline \# Students & 997,893 & 85,123 & 1279 & 717 \\
\% URM & 34 & 66 & 43 & 75 \\
$\begin{array}{l}\text { \% } \geq \text { Proficient } \\
\text { Biology I }\end{array}$ & 41.2 & 40.3 & 42.6 & 19.1 \\
$\begin{array}{l}\text { ACT Composite } \\
\begin{array}{l}\text { \% Grad Rate } \\
\text { \% Hope Scholar }\end{array}\end{array}$ & 19.9 & 18.7 & 19.9 & 17.6 \\
Eligible & 41.9 & 81.5 & 90 & 86 \\
\hline
\end{tabular}

All data for the 2015-2016 academic year was collected from the State of Tennessee Report Card (2017) or collected by school-based administrators and provided to the study team. URM = underrepresented minorities; Biology I = end of course test for Biology I. 
HS-S is a traditionally low performing high school, with reading, math, and science scores of the entering 8th graders well below the average for the school district. The student population is high minority and predominantly economically disadvantaged. HS-H is a high performing comprehensive school, with overall achievement slightly higher than the average for the district and similar in percentages to the state of Tennessee. A higher percentage of students from HS-H are eligible for the TN HOPE scholarship with the required 3.0 grade point average or a 21 composite on the ACT. For HS-S students, achievement on ACT and end of course tests has increased slightly over the past few years, but scores are still well below the MNPS and State averages. The average achievement on state tests for the entering 8th graders from schools in the HS-S zone was low (less than 30\% proficient or advanced), while the 8th graders' achievement from the HS-H middle schools was close to $75 \%$ proficient or advanced. This resulted in starting freshman classes with very different levels in reading, math, and science, leading to adaptation of the curriculum for each ISR student population. These factors impacted all aspects of the program, including recruitment and admission, retention, rigor of the coursework, and outcomes. The proportion of students from underrepresented populations is significantly higher at HS-S, requiring consideration of cultural and "real-world" factors in designing the curriculum and student projects.

The ISR program is designed as a four-year series of science content and research courses: Interdisciplinary Science (IS) I-IV and Research (R) I-III. Students may enter in the 9th grade or at the beginning of 10th grade, resulting in students who complete the course of study with 5-7 high school honors science credits. All comprehensive high schools in Nashville have implemented a career academy structure that allows students to choose a career pathway in the sophomore year. Students are required to take a minimum of three years of academy-specific courses as a component of the graduation requirements. As a recognized pathway in both $\mathrm{HS}-\mathrm{H}$ and HS-S, the ISR program satisfies the academy course requirement, and does not replace graduation requirements for either science or math. At HS-H the ISR program is in the Global Health Academy, and at HS-S the program is part of the Academy of Science and Engineering. Full course descriptions are provided in Supplemental Material.

The IS-I course is a freshman-level introductory survey course to provide students with a broad overview of the rigorous, interdisciplinary nature of the program; this allows students to get a sample of the program before committing to the full four years. As students in the career academy structure choose their pathway in the sophomore year, there is greater turnover of students (both entering and leaving the program) between IS-I and IS-II. The curriculum in the 9th and 10th grade focuses on problem-based learning units that span either 4-5 weeks (9th grade) or nine weeks (10th grade) (see Supplemental Material for full course descriptions). Freshmen meet for one period per day, with instruction focusing on gaining basic research skills to apply to whole class projects. Each unit not only incorporates multiple hands-on techniques, but also emphasizes increasing foundational science content, as well as reading and writing skills. Students learn these skills through units that focus on potential real-world problems including antibiotic resistance, catastrophic events, and the effects of pollutants on ecosystems. Students communicate their results through Powerpoint presentations, app and game design, papers, and posters. As students move into the 10th grade, the projects become more sophisticated, requiring more advanced technical ability and writing and communication skills. Sophomores take two courses as double-block periods, allowing for significant time to devote to the science projects. The primary goal for students is to learn to develop their own hypotheses and plan a strategy for carrying out their research. The exact curriculum and units covered vary per year as student interest and scientist expertise changes. Students in their junior year begin to develop their own hypothesis-driven projects, in collaboration with the scientist-teacher team, again participating in two courses (IS-III and R-II). The goal is to build an understanding of scientific research, and how science in the real world is actually conducted. Guest speakers and field trips to local science facilities are incorporated whenever possible. Students who are sufficiently advanced by the end of their junior year qualify for internships in a laboratory at Vanderbilt. In addition, all juniors are required to present their work in poster sessions at the annual district-wide STEM Expo. In their senior year, students focus on continuing their individual projects, as well as designing and executing a project to communicate their science to the public through partnerships with community agencies.

Recruitment of students for the ISR program is focused on exciting the students about the potential for studying "real" science in high school. All middle school students are encouraged to apply and complete an application packet requiring demographic information and answers to essay questions. Every effort is made to reach all students who might have an interest in pursuing rigorous STEM studies in high school and beyond, not just those with high test scores. To effectively reach all interested middle school students, the ISR program coordinator and instructors go to each feeder school in the spring to describe the program and encourage students to apply. ISR staff and faculty and middle school teachers assist students with the application process as needed.

As a potential pipeline for the ISR program, the CSO designed and implemented a program called the Day of Discovery (DoD) in 2017, funded through a National Institutes of Health SEPA award. One anticipated outcome of the DoD program is that students will be better prepared for entry into 
one of the two ISR programs. The program is modeled after the SSMV and brings 7th and 8th grade students from five middle schools to either the Vanderbilt campus or one of the ISR labs at HS-S for one-half day per week to engage in discovery and exploration. Currently, DoD students make up $37 \%$ of the ISR-H and $50 \%$ of the ISR-S 9th grade classes.

The most recent addition to the ISR program is the partnership that has developed between the CSO and Tennessee Technology University (TTU) to offer dual enrollment credits for the upper-level ISR courses through the TTU Environmental Studies Program. TTU is a Tennessee Board of Regents university, ranks as one of the top universities in the state public system, and is well-known for its engineering programs. One existing course (Introduction to Environmental Studies) and three new courses (Environmental Research I and II and Environmental Communications; 3 credit hours each) were developed during these discussions for ISR ju-

A

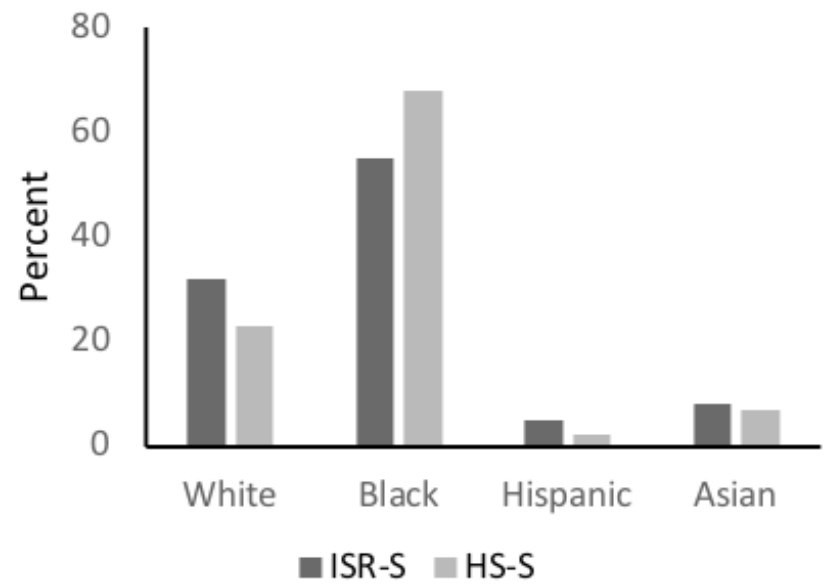

B

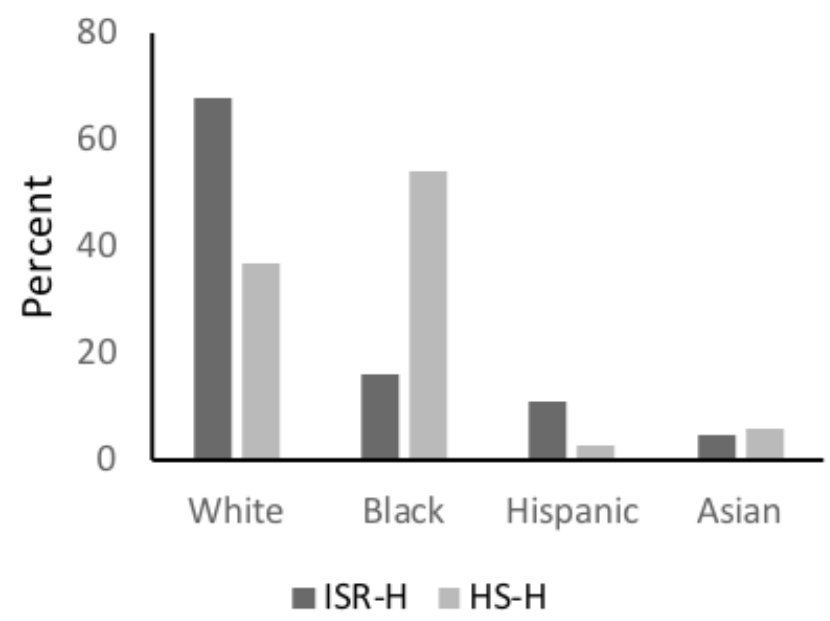

Figure 1. Demographic distributions of the ISR programs and their zoned schools. Panel A shows the percent ethnicity for the ISR-S students (dark grey) compared to the total school (HS-S; light grey). Panel B shows the ethnic breakdown for ISR-H (dark grey) compared to HS-H (light grey). niors and seniors. These students will therefore graduate with up to seven science credits on their high school transcript and 12 transferable college credits on the TTU transcript. To our knowledge this is the first partnership between MNPS and TTU, and hopefully will provide a model for other science teachers and administrators to pursue the development of additional dual enrollment courses. In this first year of eligibility, $68 \%$ of ISR-H juniors and seniors and $100 \%$ of ISR-S are taking the dual enrollment course options. We anticipate that this will increase both persistence and retention of students in the ISR program.

ISR student profile. The graduates from the ISR-S program closely mirror the demographics of the school with $32 \%$ White, 54\% Black, 5\% Hispanic, and 8\% Asian (Figure 1). The graduates from ISR-H have significantly lower numbers of underrepresented students than the school as a whole: $37 \%$ versus $61 \%$ respectively. There were more females in the ISR-S program (43\% male and 57\% female) and more males in the ISR-H program (61\% males and 39\% females) (Figure 2). The highest percentage of students in ISR-S was Black females (35\%) and the highest group in ISR-H was White males (48\%). As discussed above, a middle school program (Day of Discovery) has recently been implemented in each of the HS-H and HS-S clusters. The goal of this program is to better prepare middle school students for entry into the two ISR programs. Since the demography of each of these programs is much more closely aligned with the high school demographics, we anticipate increased diversity in future years that more closely mirrors the high school student profile.

ISR student academic achievement. The main end-of-

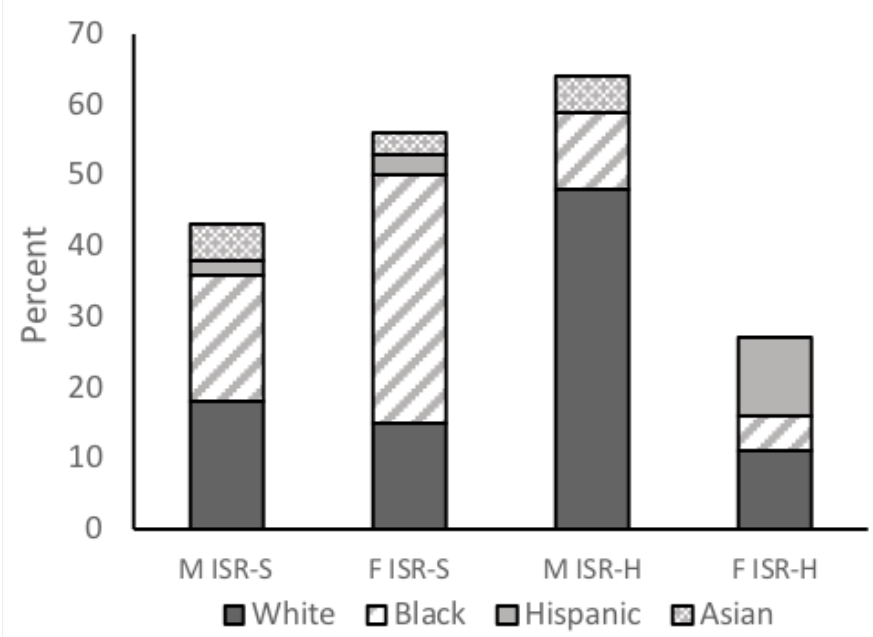

Figure 2. Comparison of the gender distribution in each ISR program and its corresponding zoned school, broken out by ethnicity. Each bar shows the percent of students who fall into White, Black, Hispanic, and Asian ethnic groups. 

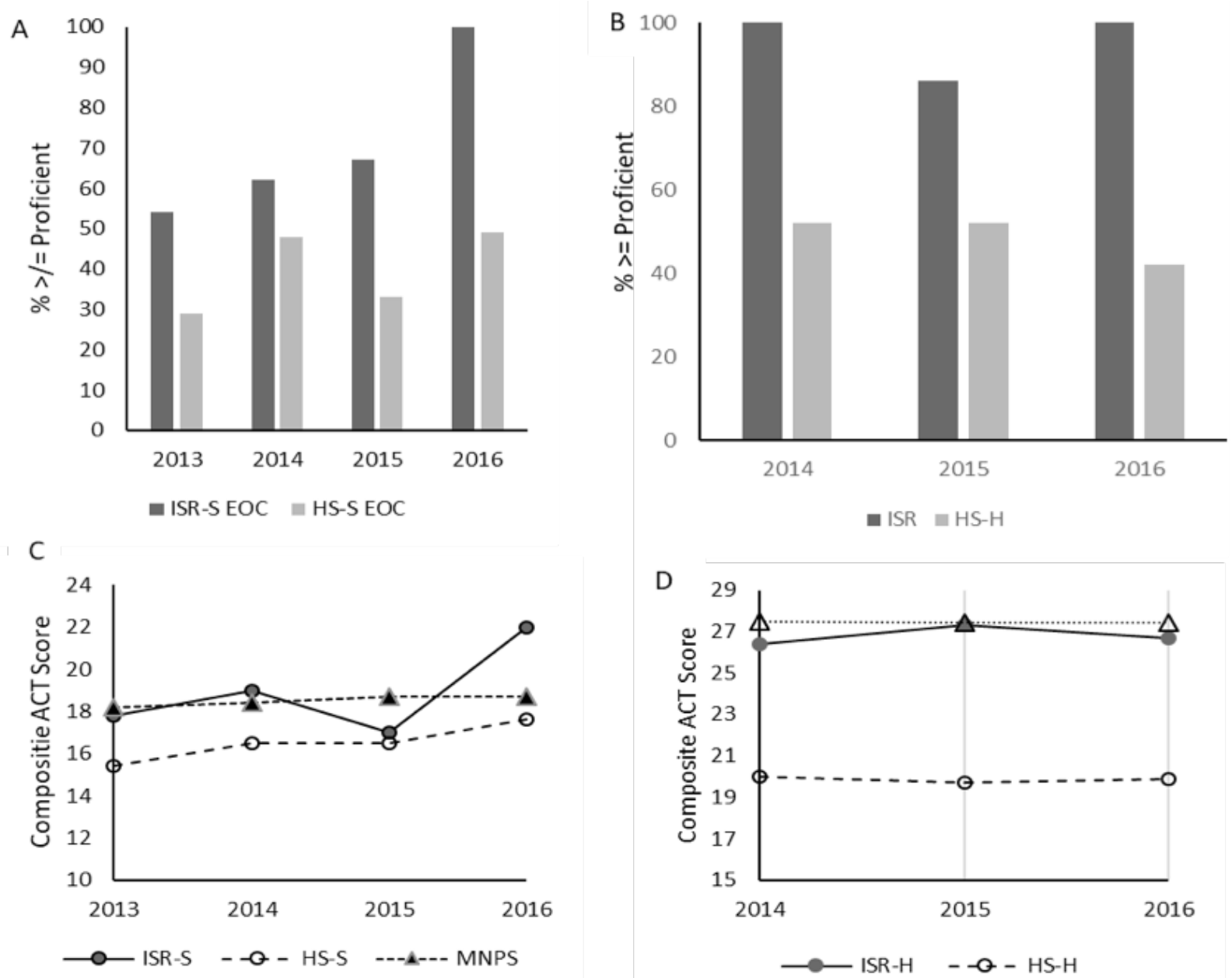

Figure 3. Biology I end of course test scores and ACT scores for each ISR program compared to its zoned school, the district (MNPS), and the top academic high school (HS-A). Panel A: the percent of ISR-S and HS-S students who scored equal to or greater than proficient on the Biology I end of course (EOC) exam. Panel B: the percent of students who scored equal to or greater than proficient of the Biology I EOC for ISR-H and HS-H. Panel C: composite ACT scores for ISR-S students in the graduating classes of 2013-2016 (solid circles) compared to all students in HS-S (open circles) and all MNPS students (triangles). Panel D: composite ACT scores for ISR-H students in the graduating classes of 2014-2016 (solid circles/solid line) compared to all students in HS-H (open circles/dashed line) and all students in the MNPS academic magnet high school (HS-A; triangles/dotted line).

course (EOC) exam that students take in Tennessee high schools is Biology I. This district-wide test provides some information about the impact of the ISR course on the students' content and reasoning skills in a science course. The range of scores between 2013 and 2016 was between 30\% and $50 \%$ for all HS-S students, while ISR-S students' scores were consistently higher than the school in every year, with $100 \%$ of the students scoring at least proficient in 2016 (Figure 3A). All of the ISR-H graduates' scores were proficient or advanced, compared to all HS students with $42 \%$ proficient or better (Figure 3B).

The ACT test has become a standard measure of college readiness in many states including Tennessee where 100\% of students take the test. The ACT sets benchmarks that define the likelihood of a student succeeding in college (ACT, 2017a). Using these benchmarks, the ACT reports that over $75 \%$ of high school graduates are not ready for college, and those who score 18 or below have less than a two-thirds chance of earning an associate's or bachelor's degree in six years (ACT, 2017b). Students who score 28 or better have a $64 \%$ chance of completing college. Since all students in MNPS take the ACT, the exam has been used as a predictor of eligibility for the state lottery HOPE scholarship (21 or greater), and for succeeding in college. In the current study, we examined the ACT scores by year, the number of students eligible for the HOPE scholarship, and the percent of students in each program who were above the ACT benchmark of 23 in science in 2016. ISR-S students scored consistently higher on the ACT test, with scores greater than HS-S students overall between 2013-2016 (Figure 3C). Although the average composite score for ISR-S students has increased since 2013, the only year that students averaged higher than the 21 HOPE benchmark was in 2016. In 2016, 16.5\% of graduates from HS-S were college ready in science (i.e. 
above the benchmark of 23 ), while $75 \%$ of ISR-S students were college ready. ISR-H students' ACT scores have been consistently high between 2014-2016, with scores ranging from 26.4 to 27.4 (Figure 3D). This is close to the average of the highest achieving academic high school in Nashville with an average ACT score of 27.5 (HS-A in Figure 3D), and significantly higher than the average score for HS-S students in general (20.0). In addition, $90 \%$ of ISR-H students were college ready in science compared to $25 \%$ of their high school classmates.

Awards and recognitions. All ISR students are required to participate in one or more of a variety of venues to orally present results of their projects or submit written articles for publication in the CSO-specific publication dedicated to high school student research (Young Scientist). As early as their sophomore year, students prepare posters for schoolwide presentations, and for the local or district STEM Expo. All ISR students have participated in these events, and have earned numerous awards and recognitions (data not shown). In the summer following their junior year, students can apply to participate in the CSO research internship program Research Experience for High School Students (REHSS). Preparation for this program varies, and not all students are ready for the rigorous research work in a Vanderbilt laboratory. As shown in Table 2, a total of 32 students have participated since 2014 - eight from ISR-S and 24 from ISR-H. REHSS students participate in an end-of-summer poster symposium, where several students from both ISR programs have been recognized for the quality of their work and presentations.

A majority of these REHSS-ISR students from both schools have also presented their research results in oral competitions at the annual Tennessee Junior Academy of Science, with 12 students winning commendations, and five

Table 1. Exploratory Factor Analysis Eigenvalues

\begin{tabular}{|c|c|c|}
\hline & ISR-S & ISR-H \\
\hline $\begin{array}{l}\text { Research Experience for } \\
\text { High School Students } \\
\text { (REHSS) }\end{array}$ & 8 & 24 \\
\hline Siemens Science Competition & 0 & 1 \\
\hline $\begin{array}{l}\text { TN Junior Academy of } \\
\text { Sciences Awards }\end{array}$ & 1 & 11 \\
\hline $\begin{array}{l}\text { Young Scientist Journal } \\
\text { Publications }\end{array}$ & 0 & 7 \\
\hline Bridges to Belmont Scholars & 15 & NA \\
\hline \multicolumn{3}{|c|}{$\begin{array}{l}\text { ISR students are encouraged to participate in extracurricular } \\
\text { STEM activites. The REHSS experience is a six-week internship } \\
\text { in a Vanderbilt laboratory; the Young Scientist is a CSO journal } \\
\text { hosting original research articles written by high school students } \\
\text { who have conducted summer research; the Bridges to Belmont is a } \\
\text { program specifically for highly talented students from two under- } \\
\text { served MNPS high schools including HS-S. }\end{array}$} \\
\hline
\end{tabular}

students winning honorable mention through first place. Students have also written scientific papers for publication in the Young Scientist (7 papers published), and one ISR-H student who submitted his work to the Siemens Math and Science competition was awarded semifinalist status in 2015. Finally, one of the most sought-after recognitions at HS-S is a scholarship program in partnership with a local university that awards full scholarships to 12-15 HS-S students each year. Since the inception of the program in 2014, 15 ISR-S students have earned this recognition, and two scholars from the first cohort graduated in four years with degrees in clinical psychology and social work.

College readiness. ACT defines college and career readiness as "the acquisition of the knowledge and skills a student needs to enroll in and succeed in credit bearing first-year courses at a postsecondary institution ... without the need for remediation" (ACT, 2017b). Looking specifically at science, the benchmark score required for classification as college ready is a 23 on the science portion of the ACT. As shown in Figure 4, 100\% of ISR-H and 63\% of ISR-S students in the class of 2016 scored a 23 or higher in science. These percentages are higher than the averages for their respective high schools as well as higher than district (MNPS) and state percentages (TN). Also shown is the percent of students who were college ready in science from the highest ranked academic high school in MNPS and the second ranked highs school in the state: HS-A.

College matriculation. To examine college matriculation for the classes of 2013-2016, data for each ISR student were submitted to the National Student Clearinghouse, a database

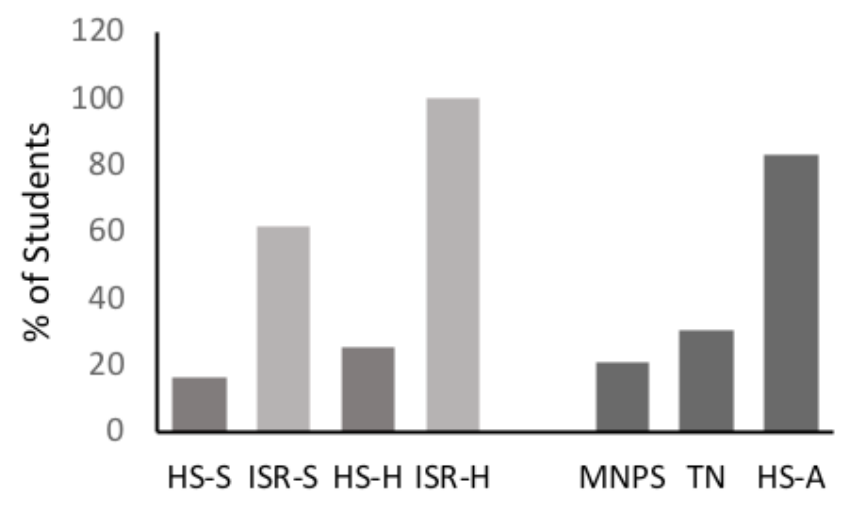

Figure 4. The percentage of students in each program and corresponding high school who attained an ACT benchmark score of 23 indicating college readiness. The number of graduates of the ISR programs at each high school who attained an ACT benchmark score of 23 (dark bars = HS-S and HS-H; light grey bars = ISR students in both high schools) is compared to the number of students from MNPS, the state of Tennessee (TN), and the academic magnet high school (HS-A). 


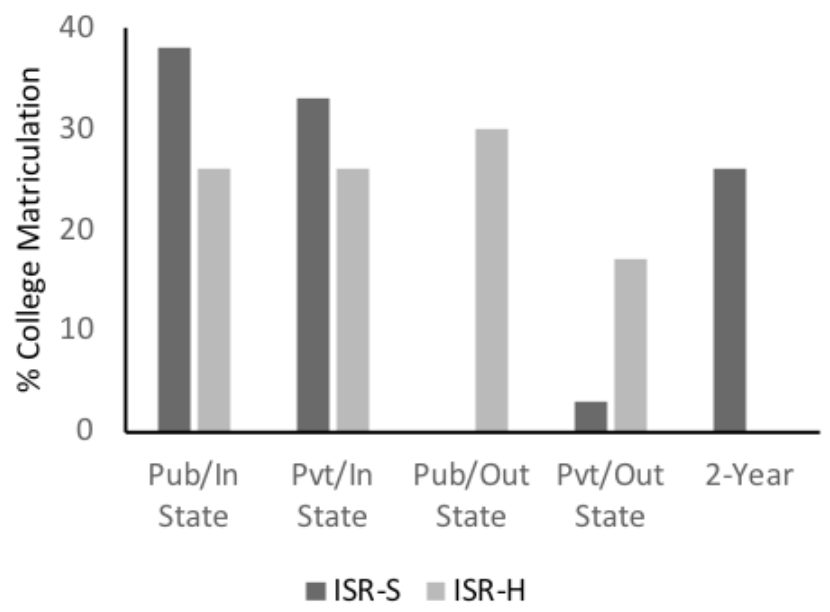

Figure 5. A comparison of types of colleges where ISR-S and ISR-H graduates have enrolled. The percent of students from ISR-S (dark bars) and ISR-H (light grey bars) who attended public in-state, private in-state, public out-of-state, and two-year colleges and universities is compared.

established in 1993 to collect enrollment and degree information from U.S. universities and colleges. Data provided for each student includes the college(s) in which the student enrolled with inclusive dates of attendance, the student's declared major, and date of graduation. To date, 96 students have graduated from the ISR program from 2013-2017, having completed freshman-senior or sophomore-senior coursework. College information was available for 64 students who graduated between 2013-2016. Of these 64 graduates, 62 are still enrolled in college and two students have completed their bachelor's degree. The breakdown of colleges attended by the graduates is shown in Figure 5. Slightly higher percentages of ISR-S graduates are attending public and private four-year in-state universities or colleges (38\% and $33 \%$ ) compared to ISR-H graduates $26 \%$ for both). Almost no ISR-S students are attending four-year public or private out of state universities, while $26 \%$ of ISR-S students are attending two-year community colleges. It should be noted that Tennessee offers free community college education for any state high school graduate, in an effort to enhance the preparation of students for study at a four-year school.

One of the anticipated outcomes of the ISR program is an increase in student interest in pursuing careers in STEM fields. Although it is still early in the program, 39 students have declared majors, with 27 of these in STEM areas. Demographically, nine of these students are Black females (7) and Black males (2) suggesting that the program has the potential to contribute to increasing diversity in the STEM pipeline.

\section{DISCUSSION}

The ISR program as described in this report was adapted from the SSMV model in an effort to expand the opportunity of a rigorous research-based program to a broader population of students. The ISR program is a course of study in the regular school curriculum, offering interested and motivated students an opportunity to enhance their depth of understanding of science content and research, to enhance achievement and interest in STEM, and to strengthen critical thinking and problem-solving skills. The students who complete the 3-4-year progressive STEM curriculum coursework show increased achievement scores compared to their peers, increasing enrollment in college, and increased interest in pursuing STEM studies in college. Importantly, supporting the success of this program, the partner school district not only financially supports the program, but has recently expanded the program to a third high school. Finally, in partnership with a Tennessee Board of Regents university, junior and senior ISR students now have the opportunity to earn up to 12 college credits.

We have classified the ISR as an "inclusive" STEM program based on enrollment and admissions criteria. A number of studies have proposed essential criteria that promote success in these programs (Laforce et al., 2016; Lynch et al., 2016; The National Academies, 2012). One such study by Lynch et al. (2016) emphasized four components that aligned most closely with the goals of the ISR program as a subset of an inclusive high school including: STEM-focused curriculum focused on college preparation; teachers with strong STEM backgrounds; individualized support within and outside of the classroom; and autonomy for curriculum and programmatic direction. The successful inclusive schools focused on STEM curricula that prepare students to pursue a college major. The ISR program is not only designed with this goal in mind, but the recent dual enrollment in partnership with TTU underscores the recognition that the curriculum is rigorous and college-level. In the first year of this TTU-ISR partnership, 75\% of the current ISR juniors and seniors have opted for the dual enrollment option. If successful, these students will graduate with not only 5-7 extra high school science electives, but will also earn up to 12 college credits.

Similar to the STEM schools, the ISR programs are cotaught by a content rich team consisting of a PhD scientist and an MNPS teacher. In addition, one of the MNPS ISR teachers hold a $\mathrm{PhD}$ in a science field, further strengthening the STEM teaching and broadening the expertise of the team. The programs also periodically bring in researchers from local universities and the community to guide student projects or lead class discussions. Students who participate in the summer internship program after their junior year also have the opportunity to work directly with a Vanderbilt researcher for six weeks, further expanding the STEM exposure for the students. Sass (2015) has reported that having a science teacher in a high school who holds at least a 
bachelor's degree in the field results in a higher likelihood of students taking STEM courses as college freshmen suggesting that students learning from Ph.D. scientists in the ISR classroom setting should increase student interest in pursuing STEM majors in college.

The ISR programs accept a broad range of students, with ethnic and gender diversity, necessitating a focus on individualized instruction. With the block scheduling, students are in ISR classes for $1-1 / 2-3$ hours per day, providing ample time for instructors to work individually with students as needed. Finally, governance of the program by the CSO was negotiated at the very beginning of the partnership development, leading to significant control over course content, scientist and teacher hiring, and student admissions and dismissals.

The anticipated outcomes for ISR graduates align with the six end-of-high school outcomes outlined in the report by Lynch and colleagues (2016). First, ISR graduates will enter college with a minimum of two required science courses (biology and chemistry), 5-7 STEM ISR electives, AP and Cambridge science courses (typically AP biology at HS-S), IB science courses (HS-H), and up to 12 university credit hours in Environmental Studies, resulting in a high level of preparation to pursue STEM in college. Second, as the results to date have demonstrated, students have been admitted to college at a rate comparable to or higher than their peers within the same school, and the majority of these students have matriculated at four-year institutions. Third, ISR students are required to complete a community outreach project in their senior year to increase their understanding of working with community partners as well as gaining skills in communicating their research results to both the scientific and lay communities. This results in greater engagement in the community and development of an understanding of the problems and challenges yet to be solved in their community. Fourth, the students have participated in a four-year progressive course of study that emphasizes all types of learning, from reading in the sciences, to communication skills, to completing complex research projects. The groundwork has been laid to encourage these students to become lifelong learners.

A number of factors influence students' decision to continue their STEM studies in college. Subotnik and Tai (2011) have reported preliminary results that suggest that students who complete research internships are more likely to complete a STEM major than their peers who do not participate in research. Students in the ISR program are encouraged to participate in the CSO-hosted six-week summer REHSS program. As shown in Table 3, eight ISR-S students and 24 ISR-H students have participated in REHSS. In addition, seven of these students published their research in the Vanderbilt high school journal, Young Scientist, and one student was awarded semi-finalist status in the prestigious Siemens competition. As the ISR program continues to mature and expand, it is anticipated that additional students will participate in REHSS. As of this writing, it is estimated that 20-25 of the current juniors will complete research internships in the upcoming summer.

Further, Wang (2013) reported that motivation was an important predictor of who will select a STEM major in college. Interestingly, according to the recent ACT STEM report, interest is highest among students from underserved populations, suggesting that this might explain our preliminary results showing a higher number of Black students in STEM majors compared to the other ethnic groups (ACT, 2016a). Studies have also shown that students who take more science and math courses as well as multiple science disciplines in high school have higher entry into STEM fields in college and completion rates of STEM degrees. Since ISR students graduate with a minimum of eight science courses, and the ISR by definition and design focus on multiple science and engineering projects and content areas, this would promote both the students' continued interest in STEM and contribute to their selection of STEM majors (ACT, 2016a).

The current ISR program has demonstrated the successes outlined above in spite of several significant barriers and challenges. First, ISR-S was started in a school that, for the last several years, has been in the lower tier of high schools in Tennessee in terms of academic achievement. Although it has increased consistently over the past seven years, this increase has been modest. The preparation of students in the feeder middle schools has continued to be below the MNPS average achievement, and students enter HS-S with reading, math, and science skills well below grade level. This has presented a challenge for the ISR program, both in attracting higher achieving students and in providing them with a grade-level but rigorous academic STEM program. As pointed out by Mervis (2011), for STEM-focused programs such as the ISR to be successful, they must be implemented in a school that already exhibits success through "a supportive, resource-rich environment". Although the HS-S administration has been supportive, and students' scores have increased slightly over the past five years, the school is still lagging behind other high schools in the district. For example, although designated as a STEM magnet in 2011, AP courses have been available only intermittently during the past ten years. The ISR program is one way that we are partnering with HS-S to enhance the preparation of students for successful matriculation at and graduation from college.

HS-H presented a very different challenge than that experienced at HS-S. HS-H is a high achieving, non-magnet, comprehensive school where the expectation by many of the students and parents is that students will progress on to a four-year college with access to scholarships. In addition, the school offers an intensive IB program that has attracted many of the students to the school. In the first several years 
of the program, parents and students (and some teachers) assumed that students could not complete both the IB and ISR programs. After completing their sophomore year, students had to choose between IB and ISR, and many of our students were lost in the process. Two important changes have decreased this attrition in the last two years. First, the students can now choose between the 4-year IB diploma program and a 2-year IB certificate program. If they choose the certificate route, they can then focus their junior and senior years on the ISR curriculum. Second, the school is now working more closely with students, parents, and the CSO to make certain that those students who wish to participate in both 4-year programs can succeed.

One important outcome for the ISR program is to prepare students for college. Although still early in the program, our results show that the 2016 ISR graduates are college-ready in science at a much higher level than either their school classmates, the district, or the state. College completion rates for the State of Tennessee have been described as "unacceptable" with less than $45 \%$ completing their degrees in six years (Alliance for Science and Technology Research in America, 2016). Additionally, there continues to be a large gap in achievement between minority and non-minority students. It has been suggested that the gap exhibited in early grade levels as soon as standardized testing begins, and continuing into the secondary years contributes to the much lower college completion rates for Black students (Quinn, et al., 2015; Sass, 2015; Vanneman, et al., 2009). The differences in achievement scores and measures such as college readiness (Figure 4) and eligibility for the State of Tennessee HOPE scholarship (Table 2) are the most likely contributors to differences in the completion of bachelor's degrees in STEM by ethnicity, differences in graduation rates, college matriculation rates, and college persistence (ACT, 2017a). Although early in our program, we have a growing number of Black students matriculating at state colleges and universities, suggesting that the ISR model has been successful in raising the college preparedness of ISR students. Of particular note is the fact that nine of the 15 STEM majors declared by ISR-S students are Black, and all nine appear on schedule to graduate from four-year colleges, prepared to enter a STEM field.

\section{CONCLUSIONS}

MNPS and the CSO have made a commitment to continue and expand the ISR program to additional local high schools. The goal of the ISR programs is to enhance students' critical thinking and problem-solving skills using STEM research and discovery as the focus. At the current point in the ISR program, increasing numbers of students each year are testing higher than their high school classmates, and are achieving ACT scores that demonstrate that they are college-ready. Although we can't rule out the possibility that the increased test scores of ISR students compared to their school-wide peers is simply a result of the program attracting higher achieving students, we can propose that the ISR course of study does provide encouragement and support to aim for higher achievement scores, and to continue STEM studies beyond high school. In support of this proposal, the SSMV program, which served as a model for the ISR, has demonstrated that SSMV students achieve at a higher level compared to a closely matched comparison group (Eeds et al., 2014). In addition, a higher percentage of SSMV graduates matriculate at top 50 colleges and universities, and pursue STEM majors than the comparison students in the non-intervention group (Shepherd, unpublished results). This suggests that one outcome of programs such as the ISR and SSMV result in students achieving at a higher level than their peers.

The goals now are to continue the research-focus and high academic requirements, and to increase the availability of this academically challenging program for more students. Two significant developments in the past year will serve to increase retention as well as interest in the program. First, the Day of Discovery is preparing 7th and 8th graders one-half day per week to participate in discovery- and research-based learning. Many of last year's 8th graders are now in one of the available high school programs (ISR-S, ISR-H, and the SSMV). We would predict that these students will bring enhanced skills and interest, and will continue through the four-year high school program. Second, the ISR has established the first dual enrollment partnership between MNPS and a four-year university in Tennessee. The opportunity to graduate from high school with over seven science courses and 12 hours of college credit will attract more students and encourage them to complete the ISR course. Finally, the school district has already requested the expansion of the ISR to a third high school, and it is quite likely that funds will be made available to expand to additional high schools, as well as create DoD programs in the middle schools that feed into these high schools. Future research directions will include defining the specific criteria for success and investigating ways to further expand the program.

\section{ASSOCIATED CONTENT}

Supplemental information with detailed course descriptions is available

\section{AUTHOR INFORMATION Corresponding Author}

Jennifer A. Ufnar, Ph.D., Department of Teaching and Learning, Peabody College of Education and Human Development; Jennifer.a.ufnar@vanderbilt.edu 


\section{Author Contributions}

The manuscript was written through contributions of all authors. All authors have given approval to the final version of the manuscript.

\section{FUNDING SOURCES}

This work was supported in part by Science Education Partnership Award \#R25OD011119 from the National Institutes of Health and through contracts with the Metro Nashville Public Schools.

\section{ABBREVIATIONS}

STEM: science, technology, engineering and mathematics; ISR: Interdisciplinary Science and Research; SSMV: School for Science and Math at Vanderbilt; CSO: Center for Science Outreach; MNNPS: Metropolitan Nashville Public Schools; HS-S: high school-S; HS-H: high school H; HS-A: academic magnet high school; EOC: end of course; REHSS: research experience for high school students; DoD: Day of Discovery; TTU: Tennessee Technological University

\section{REFERENCES}

ACT (2017a). The condition of college and career readiness. Available at http://www.act.org/content/dam/act/secured/ documents/cccr2017/CCCR_National_2017.pdf

ACT (2017b). ACT college and career readiness benchmarks. Available at: http://www.act.org/content/act/en/k12-educators-and-administrators/college-and-career-readiness/ benchmarks.html

ACT (2016a). The condition of STEM 2016 National. Available at: http://www.act.org/content/dam/act/unsecured/documents/STEM2016_52_National.pdf

ACT (2016b). The condition of STEM 2016 Tennessee. Available at: https://www.act.org/content/dam/act/unsecured/documents/STEM2016_43_Tennessee.pdf

Alliance for Science and Technology Research in America (2016). Tennessee's future: Top 40 STEM jobs in 2024. Available at: https://www.usinnovation.org/state/pdf_cvd/ASTRASTEM-on-Hill-Tennessee2016.pdf

Department of Education, Available at: https://www.ed.gov/stem

Eeds, A., Vanags, C., Creamer, J., Loveless, M., Dixon, A., Sperling, H., McCombs, G., Robinson, D., and Shepherd, V.L. (2014). The School for Science and Math at Vanderbilt: An innovative research-based program for high school students. CBE Life Science Education, 13, 297-310.

LaForce, M., Noble, E., King, H., Century, J., Blackwell, C., Holt, S., Ibrahim, A., and Loo, S. (2016). The eight essential elements of inclusive STEM high schools. International Journal of STEM education, 3, 1-11.
Lynch, S., Behrend, T., Burton, E.P., and Means, B. (2016). Comprehensive study of successful inclusive STEM high schools finds commons traits that account for strong stem outcomes.

https://mediarelations.gwu.edu/comprehensive-study-successful-inclusive-stem-high-schools-finds-common-traits-account-strong-stem

National Science and Technology Council (2013). Federal science, technology engineering and mathematics (STEM) education 5-year strategic plan. Available at: https://www. whitehouse.gov/sites/whitehouse.gov/files/ostp/Federal STEM_Strategic_Plan.pdf

National Student Clearinghouse (2017). Available at: http://www. studentclearinghouse.org/

Mervis, J. (2011). Is there a special formula for successful STEM schools? Science, May 12, 2011, p. 1. Available at: http:// www.sciencemag.org/news/2011/05/there-special-formula-successful-stem-schools

Quinn, D.M., and North C. (2015). Science achievement gaps by gender and race/ethnicity in elementary and middle school: Trends and predictors. Educational Researcher, 44(6), 336-346.

Sass, T.R. (2015). Understanding the STEM pipeline. Calder working paper 125 . http://www.caldercenter.org/sites/default/files/WP\%20125.pdf

State Report Card (2017). Available at: https://www.tn.gov/education/topic/report-card

Subotnik, R.F., and Tai, R.H. (2011). Successful education in the STEM disciplines: An examination of selective specialized science mathematics and technology-focused high schools. Presented at the National Research Council Workshop on Successful STEM Education in K-12 Schools. Available at: http://www7.nationalacademies.org/bose/ STEM_Schools_Workshop_Presentation

Successful K-12 STEM education: Identifying effective approaches in science, technology, engineering, and mathematics. (2012). Washington, DC: The National Academies, pp. 6-38.

The National Academies (2012). Successful K-12 STEM education: Identifying effective approaches in science, technology, engineering, and mathematics. Washington, DC: pp. 6-38.

Vanneman, A., Hamilton, L., Baldwin Anderson, J., and Rahman, T. (2009). Achievement Gaps: How Black and White Students in Public Schools Perform in Mathematics and Reading on the National Assessment of Educational Progress, (NCES 2009-455). National Center for Education Statistics, Institute of Education Sciences, U.S. Department of Education. Washington, DC.

Wang, X. (2013). Why students choose STEM majors. American Educational Research Journal. 50, 1081-1121. 